\title{
O SISTEMA RESPIRATÓRIO NOS LIVROS DIDÁTICOS DE CIÊNCIAS DAS SÉRIES INICIAIS: UMA ANÁLISE DO CONTEÚDO, DAS IMAGENS E ATIVIDADES
}

\section{The respiratory system in science textbooks in initial grades: analysis of the content, images and activities}

\author{
Raquel Ruppenthal ${ }^{1}$ • Maria Rosa Chitolina Schetinger ${ }^{2}$
}

\begin{abstract}
Resumo: Este trabalho busca, na análise de livros didáticos dos anos iniciais, as possíveis causas das lacunas explicativas que alunos dos anos finais apresentam sobre o sistema respiratório. Para isto, realizou-se a análise relativa a: espaço, conceitos, imagens, atividades práticas e exercícios propostos nas unidades referentes ao sistema respiratório de livros de ciências dos anos iniciais. Os resultados dessa análise apontam a existência de falhas explicativas em textos e imagens e a grande quantidade de imagens decorativas, o que pode comprometer a aprendizagem de conceitos. Constataram-se mudanças positivas nos livros do PNLD 2010, mas que a utilização dos mesmos deve ser feita com senso crítico pelos professores.
\end{abstract}

Palavras-chave: Ensino de ciências. Sistema respiratório. Livro didático. Ensino Fundamental.

\begin{abstract}
This work intends to analyze textbooks from the initial years for possible causes of the explanatory gaps that students have in their final grades of the respiratory system. To achieve this, we analyzed the space, concepts, images, practical activities and exercises in the units proposed for the respiratory system in science books within the initial years. The results of this analysis indicate the existence of failures in explanatory texts and images and a large quantity of decorative images, which can compromise the learning of concepts. Positive changes were noted in the books of PNLD 2010, but their use should be made with critical common sense by the teachers.
\end{abstract}

Keywords: Science teaching. Respiratory system. Textbook. Elementary school.

\footnotetext{
${ }^{1}$ Universidade Federal de Santa Maria (UFSM), Programa de Pós-Graduação em Educação em Ciências, Santa Maria, RS, Brasil. Rua Bento Gonçalves, 706, Cachoeira do Sul, CEP 96501-090, RS, Brasil. E-mail: rkruppenthal@gmail.com

${ }^{2}$ Universidade Federal de Santa Maria (UFSM), Programa de Pós-Graduação em Educação em Ciências, Santa Maria, RS, Brasil.
} 
Ruppenthal, R.; Schetinger, M. R. C.

\section{Introdução}

O ensino de ciências começa a ser trabalhado nos anos iniciais e perpassa toda a Educação Básica. Seu objetivo é entendido, por muitos autores, como um modo de alfabetizar cientificamente os indivíduos (LORENZETTI; DELIZOICOV, 2001; CHASSOT, 2003). Muitos dos conceitos são estudados diversas vezes pelos alunos durante seus anos de escolaridade, o que leva a esperar que eles saibam utilizar esses conceitos em questões diárias ou na resolução de problemas, mostrando serem cientificamente alfabetizados.

No entanto, ao se pesquisarem as ideias prévias de alunos da $7^{\mathrm{a}}$ série $/ 8^{\circ}$ ano do Ensino Fundamental, perceberam-se lacunas explicativas referentes a aspectos básicos sobre o sistema respiratório. Assim, surge a indagação sobre como o sistema respiratório é abordado nos anos iniciais. Para responder esta dúvida, optou-se por realizar uma análise dos livros didáticos (LD), uma vez que diversos trabalhos apontam que a análise de livros didáticos (JOTTA; CARNEIRO, 2009; MOHR, 2000; TERNES; SCHEID: GÜLLICH, 2009; XAVIER; FREIRE, MORAES, 2006) pode auxiliar no entendimento das concepções trazidas por alunos. Por outro lado, com esta análise, também será possível verificar se as avaliações dos LD realizadas pelo Ministério da Educação (MEC) proporcionam mudanças na abordagem e na correção de eventuais erros conceituais relativos ao sistema respiratório entre as escolhas de livros do Plano Nacional do Livro Didático (PNLD), que ocorrem a cada três anos.

Assim, este trabalho, primeiramente, irá esboçar a importância e as fragilidades do ensino de ciências nos anos iniciais, seguida de uma revisão sobre o uso do livro didático no ensino de ciências. Após, descreve-se a metodologia de análise, seguida das respectivas constatações obtidas pelo estudo.

\section{O ensino de ciências nas séries iniciais}

Por que ensinar ciências para crianças? Qual o objetivo de incluir as Ciências Naturais no currículo das séries iniciais? Os parâmetros curriculares nacionais (PCN) (BRASIL, 1997) descrevem, de uma forma bem geral, o que se espera do ensino de ciências nas séries iniciais, além de abordar um pouco da história da Ciência para justificar a importância dessa disciplina. Também, procuram contextualizar o ensino de conceitos buscando elementos na realidade de vida dos alunos, e descrevem algumas estratégias que poderiam ser utilizadas nas escolas para que o ensino de ciências ultrapasse a mera memorização de palavras e conceitos.

Um importante motivo para ensinar ciências é o crescente progresso científico e tecnológico alavancado no século XX e os diversos problemas decorrentes desse progresso, que exigem de todos a capacidade de usufruir dos produtos tecnológicos, mas, acima disso, possuir a capacidade crítica para perceber as consequências disso. Por isso,

[...] a apropriação de seus conceitos e procedimentos pode contribuir para o questionamento do que se vê e ouve, para a ampliação das explicações acerca dos fenômenos da natureza, para a compreensão e valoração dos modos de intervir na natureza e de utilizar seus recursos, para a compreensão dos recursos tecnológicos que realizam essas 
mediações, para a reflexão sobre questões éticas. (BRASIL, 1997, p. 21-22)

Por outro lado, a convivência com os alunos dos anos iniciais leva a constatar a grande curiosidade dos mesmos em relação a tudo que os cerca, além do fato de não terem medo de perguntar, experimentar e, até mesmo, errar. Características muito propícias para o ensino de ciências.

Poderia se afirmar que ensinar ciências nos anos iniciais deveria ter, como um fim, a Alfabetização Científica do aluno, desenvolvendo neste a capacidade de observar e ter opinião crítica em relação à Ciência e Tecnologia, "ultrapassando a mera reprodução de conceitos científicos, destituídos de significados, de sentidos e de aplicabilidade" (LORENZETTI; DELIZOICOV, 2001, p. 4).

É importante que o ensino de ciências dê sentido aos conceitos a serem ensinadosaprendidos, e não seja apenas uma lista de nomes para memorização. Nesse sentido, os próprios PCN afirmam que o "aluno é sujeito de sua aprendizagem [...], é dele o movimento de ressignificar o mundo, isto é, de construir explicações norteadas pelo conhecimento científico" (BRASIL, 1997, p. 28). Mas, e o professor, que norteia esse processo? Saberá ele das motivações que levam ao ensino de ciências nos anos iniciais?

Diversos estudos apontam para a deficiência na formação em ciências dos professores que atuam nessa faixa de escolaridade. A revisão realizada por Longhini (2008) aponta para sérios problemas no ensino de ciências, seja pelos métodos utilizados, ou pela falta de um espaço na grade horária para trabalhar ciências ou, mesmo, a falta de confiança dos professores em desenvolver conceitos de ciências, o que gera uma grande dependência dos professores em relação ao LD. Brandi e Gurgel (2002) corroboram o anteriormente mencionado, e acrescentam que as aulas de Ciências são mais comuns na escola após os alunos saberem ler e escrever, mas que, no entanto, a partir daí, as aulas passam a ser a leitura de textos, que trazem as respostas prontas para a resolução de questionários, dando a perceber que o conhecimento é pronto e acabado. Dessa forma, onde ficam a crítica e o questionamento?

Os resultados obtidos em uma pesquisa que acompanhou um grupo de professores em formação continuada em ensino de ciências indica que os professores dão mais valor ao ensino de Língua Portuguesa do que as outras disciplinas, e que, para os mesmos, o ensino de Ciências deve objetivar a educação ambiental e o ensino de conceitos (NIGRO; AZEVEDO, 2011). No entanto, o ler e o escrever podem ser desenvolvidos, também, no ensino de Ciências, uma vez que a comunicação também é importante nessa área do conhecimento.

Apesar de reconhecerem a fragilidade no ensino de ciências nos anos iniciais, Lima e Maués (2006) defendem que não é apenas o conhecimento conceitual do professor que garante boas aulas de ciências, mas, sim, sua capacidade de mobilizar diversas estratégias e saberes de outras áreas para desenvolver atividades significativas para os alunos. Ou seja, o professor deve ser um bom mediador dos processos, e não apenas um especialista em conteúdos.

Quando se fala em ensino de ciências nos anos iniciais, é necessário falar do livro didático, uma vez que, quando o profissional não conhece os conceitos, ele precisa buscá-los. E essa busca ou aperfeiçoamento, normalmente, acontece mediante a escolha do LD, que tem como uma das funções servir como fonte de consulta para os professores. Por isso, na próxima seção, será abordada uma perspectiva sobre o uso do livro didático no ensino de ciências. 


\section{O livro didático no ensino de ciências}

O LD ainda é uma das principais ferramentas utilizadas nas salas de aula. A presença dos livros didáticos nas escolas brasileiras remonta aos anos 1938, quando foi oficializada a implantação dos mesmos nas escolas (XAVIER; FREIRE, MORAES, 2006). Se, por um lado, a adoção do livro didático representa um material a mais para implementar as aulas, por outro, observa-se que os livros didáticos passaram a determinar e controlar os currículos (CARLINICOTRIM; ROSEMBERG, 1991).

Mas qual é o papel do LD no ensino de Ciências? É esperado que o livro didático de Ciências assuma uma função de estimular: a análise de fenômenos, a verificação de hipóteses e a proposição de conclusões, de maneira a promover a reflexão e a atitude investigativa dos alunos (VASCONCELOS; SOUTO, 2003) e, também, dos professores. Essa percepção do livro didático estaria em consonância com o objetivo do ensino de Ciências, que é o de formar cidadãos críticos e atuantes na sociedade (BRASIL, 1997). No entanto, ainda não há muitos estudos sobre como o livro didático é utilizado em sala de aula (CARNEIRO; SANTOS; MÓL, 2005).

Conforme estudo realizado por Megid Neto e Fracalanza (2003), pode-se afirmar três maneiras principais de utilização do LD pelo professor. Uma maneira é utilizar diversos livros, de autores e editoras diferentes, no planejamento das aulas. Outra forma de utilização é percebida quando o LD é utilizado como apoio às atividades de ensino-aprendizagem, seja através da leitura de textos, imagens ou na realização de exercícios. A outra forma de utilização é aquela onde o livro apresenta-se como uma fonte de consulta bibliográfica, tanto para o professor quanto para o aluno. Qualquer modo de utilização do LD requer que se questione o conteúdo do livro didático.

Diversos trabalhos têm questionado o LD. Na área de Ciências Naturais, destacamse: os trabalhos referentes à análise de conteúdos e correção conceitual (MOHR, 2000; NASCIMENTO; MARTINS, 2005; VASCONCELOS; SOUTO, 2003; XAVIER; FREIRE, MORAES, 2006, entre outros); os trabalhos referentes às imagens e relação texto-imagem no livro e sua função para a aprendizagem (GIBIN; KIILL; FERREIRA, 2009; JOTTA; CARNEIRO, 2009; PERALES PALACIOS; JIMÉNEZ VALLADARES, 2002; PERALES PALACIOS, 2006), além dos de Carneiro, Santos e Mól (2005), que analisam a relação do professor com os livros didáticos que apresentam uma abordagem pedagógica inovadora.

Mohr (2000) aponta ser necessário continuar realizando trabalhos de análise do livro didático para detectar eventuais problemas, bem como gerar questionamentos da própria prática docente ao utilizar o livro como fonte exclusiva e majoritária do conhecimento. A análise dos livros didáticos permite avaliar os problemas e corrigi-los, evitando que erros conceituais continuem chegando às salas de aula. Além desses, o próprio PNLD possui um método de avaliação que permite a correção e melhoria dos livros didáticos, que, além de avaliar os LD, produz um guia de orientações para auxiliar o professor na escolha do livro didático na escola.

Tendo em vista que o LD é o principal recurso utilizado em sala de aula, analisar como o sistema respiratório é abordado pelos LD de Ciências dos anos iniciais do Ensino Fundamental, além de auxiliar na construção de um perfil de conhecimentos esperados, também permitirá verificar se os livros estão em consonância com o que é esperado do ensino de Ciências e verificar a correção conceitual. 


\section{Procedimento de análise}

A fim de alcançar os objetivos deste trabalho, construiu-se o corpus da pesquisa com livros integrantes dos PNLD 2007 e 2010 (BRASIL, 2006, 2009), cujos volumes abordassem o sistema respiratório. Constituíram o corpus da pesquisa três livros do PNLD 2007 e cinco livros do PNLD 2010, totalizando oito livros, todos eles obtidos junto à biblioteca de uma escola pública.

Para cada um dos livros, verificou-se: o capítulo ou unidade de estudo referente ao sistema respiratório, nos quais foram observados o espaço do LD destinado ao estudo do sistema respiratório; os conceitos sobre o sistema respiratório que foram abordados, e a presença e inserção de atividades práticas no capítulo, cujos resultados apontam como os conceitos relativos ao sistema respiratório são abordados nos LD dos anos iniciais.

As imagens têm um papel importante no ensino por auxiliarem na percepção e construção de significados para os conceitos teóricos (JOTTA; CARNEIRO, 2009). Nesse trabalho, foram consideradas imagens todas as representações visuais, reais ou analógicas de seres, fenômenos ou objetos (CARNEIRO, 1997), com o claro intuito de atrair, comunicar ou facilitar a compreensão de um texto ou atividade. Assim, para verificar como as imagens estão inseridas nos LD e que função possuem, observou-se o número de imagens nas páginas referentes ao estudo do sistema respiratório, que foram classificadas quanto à tipologia, tendo como base Moles (1981 apud JOTTA; CARNEIRO, 2005).

Além disso, para verificar qual o objetivo da inserção das imagens no capítulo, as imagens foram classificadas quanto à funcionalidade, adaptando-se as metodologias de Carneiro (1997) e de Perales Palacios e Jiménez Valladares (2002). As imagens foram classificadas como: explicativas, quando era possível perceber que tinham como objetivo auxiliar no entendimento do texto; e de decorativas, quando sua função não tinha objetivos explicativos, mas apenas ornamentar e decorar o livro. As imagens explicativas, por sua vez podiam ser classificadas como redundantes, quando repetiam as informações do texto; ou complementares, quando traziam informações não contidas no texto.

As atividades de ensino, sejam as práticas ou as listas de exercícios normalmente indicadas nos LD, deveriam contribuir para que os alunos desenvolvessem a percepção e atenção relativas ao fenômeno em estudo, além de proporcionarem momento de reflexão sobre o conhecimento frente a novas situações e desenvolverem a capacidade de pensar (SFORNI; GALUCH, 2006). Por isso, faz-se importante observar que tipo de atividades são propostas nos LD. Para tal, realizou-se a análise das atividades indicadas para o aluno realizar no caderno, conforme o trabalho realizado por Mohr (2000).

Para todas as análises, foram construídas planilhas, as quais foram preenchidas com as informações coletadas nos LD analisados. O preenchimento das planilhas foi realizado após se olhar o capítulo ou unidade referente ao sistema respiratório duas vezes. Na terceira leitura, os critérios foram preenchidos. 
Ruppenthal, R.; Schetinger, M. R. C.

\section{Resultados}

\section{Análise da estrutura e do conteúdo}

No PNLD 2007, as três obras analisadas desenvolvem o sistema respiratório na $4^{\mathrm{a}}$ série. Com as mudanças realizadas no Ensino Fundamental e o acréscimo de um ano de escolaridade (Lei no 10.172, de 9 de janeiro de 2001) (BRASIL, 2001), o Ensino Fundamental passa a contar com nove anos, incluindo crianças entre seis e 14 anos. Os primeiros cinco anos formam os anos iniciais, e os quatro últimos anos constituem os anos finais. Assim, a antiga $4^{a}$ série equivaleria ao $5^{\circ}$ ano. Era de esperar, então, que os livros de $5^{\circ}$ ano desenvolvessem o sistema respiratório, mas três dos livros do PNLD 2010 (livros D, E e G) abordam o tema no $4^{\circ}$ ano, ou seja, nesse ano de escolaridade os alunos apresentam uma idade menor, se comparados aos alunos do $5^{\circ}$ ano. Isso leva a questionar se os alunos possuem maturidade suficiente para compreenderem aspectos mais abstratos relativos ao corpo humano e sistema respiratório, tais como as trocas gasosas e a utilização do oxigênio pelas células.

Os resultados em relação ao espaço dos LD destinados ao estudo do sistema respiratório estão expressos na Tabela 1. Essa observação pode indicar o grau de importância dada pelos autores das coleções ao estudo do sistema respiratório.

Tabela 1. Espaço destinado ao sistema respiratório nos livros analisados

\begin{tabular}{|c|c|c|c|c|c|c|c|}
\hline PNLD & Livro & $\begin{array}{l}\text { Total de } \\
\text { páginas }\end{array}$ & $\begin{array}{c}\text { Número de } \\
\text { páginas } \\
\text { referentes ao } \\
\text { corpo humano }\end{array}$ & $\%$ & $\begin{array}{l}\text { Número de } \\
\text { páginas referentes } \\
\text { ao sistema } \\
\text { respiratório }\end{array}$ & $\begin{array}{c}\text { \% em relação às } \\
\text { paginas do } \\
\text { corpo humano }\end{array}$ & $\begin{array}{c}\text { \% em relação ao } \\
\text { total de páginas } \\
\text { do livro }\end{array}$ \\
\hline \multirow[t]{3}{*}{2007} & $A$ & 184 & 55 & 29,89 & 6 & 10,91 & 3,26 \\
\hline & $B$ & 208 & 66 & 31,73 & 10 & 15,15 & 4,81 \\
\hline & C & 256 & 93 & 36,33 & 17 & 18,28 & 6,64 \\
\hline \multirow[t]{5}{*}{2010} & $\mathrm{D}$ & 200 & 66 & 33,0 & 5 & 7,58 & 3,79 \\
\hline & $E$ & 135 & 27 & 20,0 & 9 & 33,33 & 24,69 \\
\hline & $\mathrm{F}$ & 176 & 97 & 55,1 & 8 & 8,25 & 4,69 \\
\hline & $G$ & 144 & 45 & 31,3 & 12 & 26,67 & 18,52 \\
\hline & $\mathrm{H}$ & 200 & 105 & 52,5 & 7 & 6,67 & 3,33 \\
\hline
\end{tabular}

Fonte: elaborado pelas autoras a partir dos dados da pesquisa.

Todos os volumes das coleções dos anos iniciais, normalmente, estão organizados de acordo com os blocos temáticos indicados nos PCNs (a saber: Ambiente; Ser Humano e Saúde; Recursos Tecnológicos, e Terra e Universo). Cada livro destina uma quantidade de páginas para abordar todos os blocos, e, por isso, o número de páginas dedicadas ao corpo humano varia de livro para livro. Assim, os sistemas são abordados no bloco Ser Humano e Saúde, normalmente nos dois últimos volumes da coleção. Repare-se que apenas os livros F e H tratam do corpo humano em mais de $50 \%$ da obra.

Se compararmos o espaço destinado ao estudo do corpo humano considerando os livros analisados em cada PNLD, percebe-se que, no PNLD 2010, há uma maior variação do número de páginas destinadas ao estudo do corpo humano. Neste PNLD, a média é de 68 
páginas. Em contraste, o livro E utiliza apenas 27 páginas, enquanto o livro H utiliza 105 páginas para desenvolver conteúdos referentes ao corpo. O pequeno número de páginas leva a pensar que os conteúdos podem ser explorados superficialmente.

Em relação ao número de páginas destinadas ao estudo do sistema respiratório, a média de páginas dos livros analisados do PNLD 2007 é de 11 páginas, enquanto, no PNLD 2010, é de 8,2 páginas. No entanto, se considerarmos o percentual (razão entre páginas do sistema respiratório em relação ao total de páginas destinadas ao corpo humano), percebe-se que os livros $\mathrm{E}$ e $\mathrm{G}$ dão maior ênfase ao sistema respiratório do que os outros livros analisados.

Mais importante do que o espaço destinado aos conteúdos, é a abordagem dos conceitos no capítulo. Assim, a segunda parte da análise do conteúdo traz aspectos relativos aos conceitos abordados em cada livro, cujos resultados estão indicados na Tabela 2.

Tabela 2. Conceitos relativos ao sistema respiratório abordados em cada livro

\begin{tabular}{|c|c|c|c|c|c|c|c|c|}
\hline \multirow{3}{*}{ Conceitos abordados } & \multicolumn{8}{|c|}{ Livros } \\
\hline & \multicolumn{3}{|c|}{ PNLD 2007} & \multicolumn{5}{|c|}{ PNLD 2010} \\
\hline & A & B & C & D & $E$ & $\mathbf{F}$ & G & $\mathbf{H}$ \\
\hline Importância e função & $\mathrm{x}$ & & $\mathrm{x}$ & & $\mathrm{x}$ & & $\mathrm{x}$ & $\mathrm{x}$ \\
\hline Constituição/anatomia & $\hat{x}$ & $\mathrm{x}$ & $\hat{x}$ & $\mathrm{x}$ & $\hat{x}$ & $x$ & $\hat{x}$ & $\hat{x}$ \\
\hline Movimentos respiratórios & $\hat{x}$ & $\hat{x}$ & $\hat{x}$ & $\hat{x}$ & $\hat{x}$ & $\hat{x}$ & $\hat{x}$ & \\
\hline Trocas gasosas & $x$ & $x$ & & $\hat{x}$ & & $\hat{x}$ & & $x$ \\
\hline Composição do ar inspirado e expirado & & $x$ & & $x$ & $\mathrm{x}$ & $x$ & & $\mathrm{x}$ \\
\hline Fotossíntese & & $x$ & & & & & & \\
\hline
\end{tabular}

Fonte: elaborado pelas autoras a partir dos dados da pesquisa.

Dos LD analisados, cinco falam sobre a importância da respiração. Porém, das explicações oferecidas, apenas os livros $\mathrm{G}$ e $\mathrm{H}$ abordam a inter-relação entre o sistema digestório e o respiratório no processo de obtenção de energia, numa linguagem acessível. As demais explicações são simplistas, como, por exemplo, a explicação do livro A: "A respiração é a maneira pela qual o corpo elimina o gás carbônico que ele produz a todo momento e que não pode se acumular. Em outras palavras, a respiração é uma troca gasosa entre o corpo e o ambiente" (CARVALHO; SAMPAIO; ENGELSTEIN, 2005, p. 27).

Todos os LD analisados abordam a constituição/anatomia do sistema respiratório, normalmente apresentando os órgãos em textos e imagens. Apesar disso, os livros B, C, D, E, F, G e H simplificam a constituição, ignorando, sobretudo: os bronquíolos, alvéolos, faringe, laringe e brônquios. Ou então, utilizam analogias comparando os brônquios e bronquíolos a galhos de árvores, ou a tubos. O diafragma é outro órgão negligenciado no estudo anatômico do sistema respiratório, apesar de sua atuação nos movimentos respiratórios.

O livro F, ao abordar a constituição do sistema respiratório, afirma que

$\mathrm{O}$ ar que você inspira passa pelo nariz, boca, faringe, laringe, traqueia e segue pelos brônquios direito e esquerdo até os pulmões. Nos pulmões, os brônquios se ramificam, formando estruturas que se pare- 
cem com ramos de uma árvore, até atingirem os alvéolos pulmonares. (FONSECA; ANDRADE; MORAIS, 2007, p. 49, grifos nossos)

No entanto, o texto não esclarece que a boca é uma via alternativa para a respiração, no caso de a pessoa estar com o nariz obstruído; e nem aponta a importância de se respirar pelo nariz, pois este pode filtrar, aquecer e umedecer o ar. Nesse caso, o professor precisará interferir e questionar. Além disso, a analogia dos brônquios com ramos de árvores pode levar o aluno a formar ideias errôneas.

Em relação aos movimentos respiratórios, há explicações que se referem apenas à entrada e saída do ar (livros B, C, D, E e F); outro livro explica a função do diafragma na entrada e saída do ar (livro A), e um, além de explicar a entrada e saída do ar pela ação do diafragma, também explica a diferença na composição do ar inspirado e expirado (livro G). O fato de os LD ignorarem a ação do diafragma nos movimentos respiratórios pode ser um dos motivos por que muitos alunos afirmam ser do nariz a função de fazer o ar entrar no corpo.

Apesar de ser um conceito bastante abstrato para crianças, as trocas gasosas são abordadas em cinco livros, e podemos agrupar as explicações em dois grupos. O primeiro, que explica as trocas gasosas como um fenômeno que acontece ao nível de alvéolos, sem mencionar o sangue (livros $\mathrm{B}$ e $\mathrm{C}$ ); o outro, que acrescenta o sangue como o agente que transporta $\mathrm{o}$ oxigênio e o gás carbônico (livros A, F e G). O livro G ainda cita as células, como consumidoras de oxigênio e produtoras do gás carbônico.

Em relação à composição do ar inspirado e expirado, dos livros que tratam o tema, um deles fala nos demais gases que constituem o ar atmosférico (livro F). Os demais, falam apenas em gás oxigênio e gás carbônico. $O$ livro $G$ aborda esse tema, porém fora do capítulo do sistema respiratório.

Um dos livros analisados aborda o tema fotossíntese. Numa visão global, parece ser lógico tratar da fotossíntese, uma vez que é através dela que o oxigênio é disponibilizado na atmosfera, além de ela ser o processo complementar da respiração. No entanto, esse é um conhecimento que pode dificultar ou causar confusões na aprendizagem. No caso do livro analisado, há uma imagem mostrando o processo de respiração das plantas, mas não há indicação de um título. Se o aluno não ler o texto, pode haver distorções na compreensão, podendo o aluno imaginar que a fotossíntese é a respiração das plantas.

Outro aspecto analisado nos livros foi a inserção de atividades práticas referentes ao sistema respiratório. Foram consideradas atividades práticas todas "as atividades que envolvessem ativamente o aluno; lidando com objeto ou com o processo em questão; nos domínios psicomotor, cognitivo ou afetivo" (HODSON, 1994 apud GUSMÃO; CAPILÉ; GOLDBA$\mathrm{CH}, 2011$ ). Todos os livros analisados apresentaram atividades práticas. Sete livros (livros A, B, D, E, F, G e H) utilizam o modelo do sistema respiratório para a explicação e/ou visualização dos movimentos respiratórios. No PNLD 2010, essa atividade é proposta no início ou durante as explicações, e pressupõe a interação do aluno com o modelo, a fim de construir explicações. Isso está de acordo com os pressupostos encontrados nos PCN, de que o aluno deve ser ativo na construção e articulação de saberes.

O livro $C$ apresenta quatro atividades práticas, propondo a observação do corpo em repouso e após a realização de atividade física, incentivando o aluno a contar os movimentos respiratórios e o pulso, realizando anotações em forma de tabela. Após, os alunos devem 
comparar os resultados, discutir as causas dos resultados, e, enfim, escrever as conclusões. Importante destacar que esse livro utiliza o tema transversal saúde para abordar o sistema respiratório e cardiovascular conjuntamente. No entanto, apesar de bem contextualizado, este livro apresenta poucos conceitos ou conhecimento relativo aos sistemas em estudo.

O livro A propõe a construção de um aparato para medir quanto ar cabe nos pulmões. No entanto, não faz relações com a teoria, apenas procura desenvolver as habilidades de manipular, registrar e comparar dados. A mesma atividade é proposta pelo livro $G$, como atividade inicial do capítulo. Em relação à atividade, o livro propõe duas questões que requerem a análise e comparação de dados, mas também não fica claro qual a intenção ou relação da atividade com o capítulo.

O PNLD 2007 apresenta um total de sete atividades práticas, enquanto o total de atividades práticas do PNLD 2010 é de 13. Nos livros analisados, percebeu-se que a abordagem das atividades práticas no PNLD 2010 ocorre no decorrer do capítulo, e há questionamentos referentes à atividade. Além disso, outras levam o aluno a observar os movimentos respiratórios em si, a fim de que o aluno experimente e compreenda os conceitos tratados. Outra constatação é a de que, no PNLD 2010, há uma preocupação em considerar os conhecimentos prévios dos alunos sobre o sistema respiratório. Para isso, se valem de atividades como: pedir para os alunos desenharem o caminho do ar. Este é retomado durante o processo ou no final, a fim de que os alunos possam verificar possíveis erros e realizar as adequações necessárias. Além disso, dois livros exploram a questão lúdica e artística (livros E e H), quando sugerem ao aluno representar o sistema respiratório com massinha de modelar.

É importante ressaltar que a atividade prática, sem um objetivo, é simplesmente mais uma atividade. Elas são importantes para auxiliar o aluno na construção do conhecimento e, para isso, é necessário que, além de estimular o aluno a pensar o que e por que algo acontece, exista um vínculo com a teoria. Nos LD analisados, o objetivo das atividades práticas nem sempre é explícito, cabendo novamente ao professor fazer as devidas relações.

\section{Análise das imagens}

As imagens são um recurso cada vez mais presente nos LD, mas alguns estudos vêm apontando que, nem sempre, essas imagens realizam a função pedagógica a elas atribuída (SOUZA; GOUVEA, 2009). Após a verificação das imagens nos livros analisados, chegou-se aos resultados apontados na Tabela 3 . Ao cruzarmos o número de imagens com o número de páginas referentes ao sistema respiratório (Tabela 2), percebe-se que o livro E possui a menor incidência de imagens (em média 1,3 imagens/página), enquanto o livro $\mathrm{C}$ possui a maior incidência (em média 3,9 imagens/página). O grande número de imagens pode contribuir para desviar a atenção do aluno para fatos importantes, ou exigir uma grande carga cognitiva para processar a informação (MATOS et al., 2010).

Os principais tipos de imagens utilizadas nos LD dos anos iniciais são: desenhos, fotografias e esquemas. O livro A traz uma equação, utilizando signos normalizados, o que exige um grau de conhecimento elevado para sua interpretação, por isso não sendo indicadas para livros dos anos iniciais. O tipo de imagem que prevalece em ambos os PNLD é do tipo desenho. Destacam-se os livros C, F e G, nos quais 73,1\%, 58,8\% e 88,5\% das imagens são desenhos. Uma possível explicação para o alto número de desenhos é o fato de as crianças 
Ruppenthal, R.; Schetinger, M. R. C.

utilizarem o desenho para se expressar, e, no caso, os livros procuram atrair a atenção do aluno com desenhos.

As fotografias são consideradas as representações mais reais, no entanto, após a análise, percebe-se que, nos livros do PNLD 2010, houve uma redução em sua utilização. O mesmo ocorre com os desenhos. Apenas os esquemas apresentam maior frequência em relação aos livros do PNLD 2007.

A segunda etapa da análise das imagens refere-se à função desempenhada pela imagem no texto, cujos resultados estão expressos na Tabela 4.

Percebe-se que, nos livros C e F, o principal propósito das imagens é decorar e ornamentar as páginas. Isso pode levar o aluno a se dispersar e dificultar a aprendizagem. $\mathrm{O}$ excesso de imagens também pode aumentar a carga cognitiva exigida do aluno (MATOS et al., 2010). Por outro lado, os livros A, B, E, G e H utilizam as imagens com o propósito de auxiliar o entendimento dos conceitos abordados no texto, o que leva a considerar que a maioria dos livros utiliza as imagens como recurso facilitador da aprendizagem.

Tabela 3. Análise quanto aos tipos de imagens

\begin{tabular}{ccccccccccc}
\hline PNLD & Livro & Total de imagens & Fotografias & $\%$ & Desenhos & $\%$ & Esquemas & $\%$ & Outros & $\%$ \\
\hline 2007 & A & 11 & 3 & 27,3 & 4 & 36,4 & 3 & 27,3 & 1 & 9,1 \\
& B & 19 & 9 & 47,4 & 2 & 10,5 & 8 & 42,1 & 0 & 0 \\
& C & 67 & 10 & 14,9 & 49 & 73,1 & 7 & 10,4 & 1 & 1,5 \\
& Total & $\mathbf{9 7}$ & $\mathbf{2 2}$ & $\mathbf{2 2 , 7}$ & $\mathbf{5 5}$ & $\mathbf{5 6 , 7}$ & $\mathbf{1 8}$ & $\mathbf{1 8 , 6}$ & $\mathbf{2}$ & $\mathbf{1 0 , 6}$ \\
$\mathbf{2}$ & D & 12 & 5 & 41,7 & 4 & 33,3 & 4 & 33,3 & 0 & 0 \\
& E & 12 & 3 & 25,0 & 1 & 8,3 & 8 & 66,7 & 0 & 0 \\
& F & 18 & 5 & 27,8 & 11 & 61,1 & 2 & 11,1 & 0 & 0 \\
& G & 26 & 0 & 0,0 & 23 & 88,5 & 3 & 11,5 & 0 & 0 \\
& H & $\mathbf{1 1}$ & $\mathbf{3}$ & 27,3 & 3 & 27,3 & 5 & $\mathbf{4 5 , 5}$ & 0 & 0 \\
& Total & $\mathbf{7 9}$ & $\mathbf{1 6}$ & $\mathbf{2 0 , 3}$ & $\mathbf{4 2}$ & $\mathbf{5 3 , 2}$ & $\mathbf{2 2}$ & $\mathbf{2 7 , 8}$ & $\mathbf{0}$ & $\mathbf{0}$ \\
\hline
\end{tabular}

Fonte: elaborado pelas autoras a partir dos dados da pesquisa.

Tabela 4. Análise da funcionalidade das imagens

\begin{tabular}{|c|c|c|c|c|c|c|c|c|}
\hline \multirow[b]{3}{*}{ PNLD } & \multirow[b]{3}{*}{ Livros } & \multirow[b]{3}{*}{ Total de imagens } & \multicolumn{6}{|c|}{ Funções } \\
\hline & & & \multicolumn{4}{|c|}{ Explicativa } & \multirow[b]{2}{*}{ Decorativa } & \multirow[b]{2}{*}{$\%$} \\
\hline & & & Redundante & $\%$ & Complementar & $\%$ & & \\
\hline \multirow[t]{4}{*}{2007} & A & 11 & 6 & 54,5 & 0 & 0,0 & 5 & 45,5 \\
\hline & B & 19 & 9 & 47,4 & 2 & 10,5 & 8 & 42,1 \\
\hline & C & 67 & 4 & 6,0 & 6 & 9,0 & 57 & 85,1 \\
\hline & Total & 97 & 19 & 19,6 & 8 & 8,2 & 63 & 64,9 \\
\hline \multirow[t]{6}{*}{2010} & D & 12 & 2 & 16,7 & 3 & 25,0 & 7 & 58,3 \\
\hline & $E$ & 12 & 3 & 25,0 & 5 & 41,7 & 4 & 33,3 \\
\hline & $\mathbf{F}$ & 18 & 2 & 11,1 & 2 & 11,1 & 14 & 77,8 \\
\hline & G & 26 & 3 & 11,5 & 12 & 46,2 & 11 & 42,3 \\
\hline & H & 11 & 7 & 63,6 & 0 & 0,0 & 4 & 36,4 \\
\hline & Total & 79 & 17 & 21,5 & 22 & 27,8 & 40 & 50,6 \\
\hline
\end{tabular}

Fonte: elaborado pelas autoras a partir dos dados da pesquisa. 
Em relação às imagens explicativas, percebe-se um predomínio das explicativas redundantes, sendo que apenas os livros E e G utilizam as explicativas complementares em maior proporção. Nesse caso, é importante enfatizar o papel do professor para auxiliar na interpretação das imagens, a fim de evitar entendimentos errôneos. O livro D chama atenção pelo fato de deixar a maior parte da informação a cargo da imagem. Uma dessas imagens é referente à anatomia do sistema respiratório, mas, nesse caso, apresenta questionamentos que procuram auxiliar o aluno na compreensão. No entanto, o mesmo não é verificado na imagem que traz informações sobre as trocas gasosas, que exige a total obtenção de informações da imagem. Nesse caso, novamente, será o professor que deverá realizar as intervenções necessárias a fim de que os alunos compreendam o fenômeno.

Outra constatação é a de que, nos livros do PNLD 2007, a maior parte das imagens explicativas indica que as cores usadas não são reais. Nos do PNLD 2010, além de indicarem o uso de cores fantasia, também referem-se à escala, e isso representa uma melhoria em relação ao conteúdo visual. No entanto, em todos os livros analisados, normalmente não há legenda para auxiliar na interpretação dela, e são poucos os livros em que o texto remete à imagem, o que também exige maior carga cognitiva do aluno.

A análise dos valores totais de cada categoria sobre a funcionalidade das imagens indica uma redução nas imagens meramente decorativas. Enquanto, no PNLD 2007, 70,6\% das imagens são decorativas, no PNLD 2010, elas representam 50\% do total de imagens. Isso é importante, pois as imagens decorativas, além de não contribuírem para a aprendizagem, ainda podem desviar a atenção do aluno (PERALES PALACIOS; JIMÉNEZ VALLADARES, 2002), da mesma maneira que imagens muito simplificadas também não auxiliam na compreensão do fenômeno (PERALES PALACIOS, 2006).

\section{Análise das atividades}

As atividades podem ser entendidas como um momento onde o aluno utilizará as informações e conceitos aprendidos para resolver os problemas. Ou seria de esperar que proporcionassem isso ao aluno. Por isso, verificaram-se as atividades propostas para o sistema respiratório, cujos resultados estão apresentados na Tabela 5 .

Tabela 5. Resultados da análise das atividades propostas

\begin{tabular}{|c|c|c|c|c|c|c|c|c|c|c|c|c|}
\hline \multirow[b]{2}{*}{ PNLD } & \multirow[b]{2}{*}{ Livros } & \multirow[b]{2}{*}{$\begin{array}{l}\text { Número de } \\
\text { exercícios }\end{array}$} & \multicolumn{10}{|c|}{ Tipos de exercícios } \\
\hline & & & Análise & $\%$ & $\begin{array}{c}\text { Resolução de } \\
\text { problemas }\end{array}$ & $\%$ & Cópia & $\%$ & $\begin{array}{l}\text { Atividades } \\
\text { extralivro }\end{array}$ & $\%$ & $\begin{array}{c}\text { Resposta } \\
\text { aberta }\end{array}$ & $\%$ \\
\hline \multirow[t]{4}{*}{2007} & $A$ & 9 & 2 & 22,2 & 0 & 0,0 & 2 & 22,2 & 0 & 0,0 & 5 & 55,6 \\
\hline & B & 26 & 11 & 42,3 & 7 & 26,9 & 3 & 11,5 & 3 & 11,5 & 2 & 7,7 \\
\hline & C & 37 & 16 & 43,2 & 1 & 2,7 & 4 & 10,8 & 3 & 8,1 & 13 & 35,1 \\
\hline & Total & 72 & 29 & 40,3 & 8 & 11,1 & 9 & 12,5 & 6 & 8,3 & 20 & 27,8 \\
\hline \multirow[t]{6}{*}{2010} & D & 6 & 4 & 66,7 & 2 & 33,3 & 0 & 0,0 & 0 & 0,0 & 0 & 0,0 \\
\hline & $\mathrm{E}$ & 14 & 9 & 64,3 & 1 & 7,1 & 1 & 7,1 & 1 & 7,1 & 2 & 14,3 \\
\hline & $\bar{F}$ & 20 & 17 & 85,0 & 0 & 0,0 & 1 & 5,0 & 0 & 0,0 & 2 & 10,0 \\
\hline & G & 22 & 13 & 59,1 & 1 & 4,5 & 2 & 9,1 & 0 & 0,0 & 6 & 27,3 \\
\hline & $\mathbf{H}$ & 16 & 12 & 75,0 & 0 & 0,0 & 1 & 6,3 & 0 & 0,0 & 3 & 18,8 \\
\hline & Total & 78 & 55 & 70,5 & 4 & 5,1 & 5 & 6,4 & 1 & 1,3 & 13 & 16,7 \\
\hline
\end{tabular}

Fonte: elaborado pelas autoras a partir dos dados da pesquisa. 
Os resultados apontam para o predomínio das atividades de análise, nos livros de ambos os PNLD, e esse número aumenta no PNLD 2010. As demais categorias de atividades diminuem. Importante ressaltar que as atividades de cópia são bem reduzidas. Chama atenção o fato de que as atividades extralivro, que estimulam o aluno a buscar informações em outras fontes, recebem menor atenção dos LD do PNLD 2010, pois esse tipo de atividade aparece em apenas um livro (E). Uma possível explicação para esse fato é a maior presença de textos informativos de outras fontes, não exigindo que o aluno busque essas informações em outras fontes.

Em relação ao local do capítulo onde as atividades são propostas, apenas dois livros apresentam as atividades no final do capítulo ( $\mathrm{A}$ e $\mathrm{G}$ ), enquanto os demais propõem as atividades no decorrer do capítulo. Essa é uma característica importante, pois leva em consideração o aluno como agente ativo na construção de seu conhecimento.

\section{Considerações}

A realização deste trabalho não objetivou a classificação dos livros, mas indicar aspectos que exigem a atenção do professor ao utilizar o LD como um recurso em sala de aula. É necessário considerar a importância dos LD nas escolas, uma vez que é um material amplamente distribuído na rede pública de ensino, e, em muitas escolas, é um dos únicos recursos disponíveis além do quadro e giz. No entanto, a escolha e utilização do LD devem ser feitas com cuidado, sendo importante que os professores tenham consciência de que há problemas que precisam ser observados ao utilizarem o livro como referência na elaboração das aulas. Ou seja, a utilização deles deve ser feita com senso crítico, uma vez que a maioria apresenta problemas, sejam em relação às imagens ou, mesmo, as informações.

Em relação aos conteúdos relativos ao sistema respiratório, constata-se que a transposição didática, muitas vezes, simplifica os processos ao extremo. Os livros, dessa maneira, podem contribuir para a formação de concepções simplistas da respiração. Os livros analisados abordam os conceitos básicos da respiração, porém é necessário questionar até que ponto eles devem tratar aspectos mais abstratos, uma vez que os PCN (BRASIL, 1997, p. 28) apontam que, "nos primeiros ciclos o aluno constrói repertórios de imagens, fatos e noções, sendo que o estabelecimento dos conceitos científicos se configura nos ciclos finais". Isso não quer dizer que não se possam desenvolver conceitos, mas que esse não é o maior objetivo do ensino de Ciências nos anos iniciais. Importante ressaltar que os LD analisados trazem alguns erros conceituais, ou informações incompletas, e, nesses casos, o professor precisará interferir.

As atividades práticas foram encontradas nos LD, mas algumas coleções ainda necessitam atribuir a elas um objetivo para a aprendizagem e sua relação com o conteúdo. Alguns dos livros que constituem as obras indicadas no PNLD 2010 (BRASIL, 2009) conseguem construir essa relação entre teoria e prática, no entanto, isso precisa ser estendido às demais coleções. Em relação às atividades propostas para serem realizadas no caderno, a maioria das atividades representa situações que requerem do aluno a análise e utilização de conceitos. Isso é importante, pois auxilia no desenvolvimento das habilidades defendidas nos PCN e que contribuem para a formação crítica e reflexiva dos alunos. 
O sistema respiratório nos livros didáticos ...

As imagens estão bem presentes nas obras analisadas, o que é uma tendência no mercado editorial. No entanto, sobretudo no PNLD 2007 (BRASIL, 2006), as imagens eram meramente decorativas, ou seja, não tinham real função na aprendizagem. Em relação às imagens, também foram percebidas falhas e detalhes que podem contribuir para um entendimento errôneo, tais como a representação muito simplificada, omitindo órgãos constituintes do sistema respiratório, ou imagens incompletas, nas quais não há uma continuidade entre as vias aéreas superiores e inferiores. Apesar disso, é importante ressaltar que mudanças importantes ocorreram entre os PNLD, especialmente no que se refere à indicação da utilização de cores fantasia e escala. No entanto, ainda faz-se necessário que os textos refiram-se às imagens, o que só foi verificado em um dos livros da amostra.

De uma maneira geral, é possível afirmar que os livros apresentaram modificações significativas em relação à apresentação e estratégias de interação do aluno com o conteúdo, mas que ainda há melhorias a serem realizadas. Os resultados dessa análise também permitem afirmar que os alunos dos anos finais poderiam ter melhores explicações sobre a respiração, uma vez que todos os livros analisados apresentam os principais conceitos relativos ao sistema respiratório. Em relação à utilização dos LD, seria interessante acompanhar como os professores desenvolvem seu trabalho com o livro didático, e como os alunos interagem com o livro, a fim de se compreender melhor a construção do conhecimento pelos alunos.

\section{Referências}

BONDUKI, S.; CAMARGO, C. R. Ciências $-4^{\circ}$ ano. São Paulo: Companhia Editora Nacional, 2008.

BRANDI, A. T. E.; GURGEL, C. M. A. A alfabetização científica e o processo de ler e escrever em séries iniciais: emergências de um estudo de investigação-ação. Ciência \& Educação, Bauru, v. 8, n. 1, p. 113-125, 2002. Disponível em: <http://www.scielo.br/pdf/ ciedu/v8n1/09.pdf>. Acesso em: 18 jan. 2012.

BRASIL. Lei n $\mathbf{n}^{\mathbf{1 0}}$ 10.172, de 9 de janeiro de 2001. Aprova o Plano Nacional de Educação e dá outras providências. Brasília: Presidência da República, 2001. Disponível em: <http:// www.planalto.gov.br/ccivil_03/leis/leis_2001/110172.htm>. Acesso em: 10 ago. 2013.

2009.

Ministério da Educação. Guia de livros didáticos: PNLD 2010: ciências. Brasília,

. Ministério da Educação. Guia do livro didático 2007: ciências: séries/anos iniciais do ensino fundamental. Brasília, 2006.

Ministério da Educação. Secretaria de Educação Básica. Ensino fundamental de nove anos: orientações gerais. Brasília, 2004. Disponível em: <http://portal.mec.gov.br/ seb/arquivos/pdf/Ensfund/noveanorienger.pdf>. Acesso em: 28 jan. 2012.

. Ministério da Educação. Secretaria de Educação Fundamental. Parâmetros

curriculares nacionais: ciências naturais. Brasília, 1997. 
Ruppenthal, R.; Schetinger, M. R. C.

CARLINI-COTRIM, B.; ROSEMBERG, F. Os livros didáticos e o ensino para a saúde: o caso das drogas psicotrópicas. Revista de Saúde Pública, São Paulo, v. 25, n. 4, p. 299305, 1991.

CARNEIRO, M. H. S. As imagens no livro didático. In: ENCONTRO

NACIONAL DE PESQUISA EM ENSINO DE CIÊNCIAS, 1., 1997, Águas de Lindóia. Atas... São Paulo: ABRAPEC, 1997. p. 366-373.

CARNEIRO, M. H. S.; SANTOS, W. L. P.; MÓL, G. S. Livro didático inovador e professores: uma tensão a ser vencida. Ensaio: Pesquisa em Educação em Ciências, Belo Horizonte, v. 7, n. 2, p. 119-130, 2005.

CARVAlHO, A. F. et al. Ciências: ponto de partida -4 a série. São Paulo: Sarandi, 2005. CARVALHO, A. F.; SAMPAIO, F. A.; ENGELSTEIN, M. Ciências: ponto de partida: $4^{\circ}$ série. São Paulo: Sarandi, 2005.

CHASSOT, A. Alfabetização científica: uma possibilidade para a inclusão social. Revista Brasileira de Educação, Rio de Janeiro, n. 22, p. 89-100, 2003.

COElHO, G.; GIOVANETTTI, G. Projeto conviver: ciências - $4^{\circ}$ ano. São Paulo: Moderna, 2008.

CRUZ, J. L. C. (Ed.). Projeto Pitanguá: ciências - $4^{\circ}$ ano. 2. ed. São Paulo: Moderna, 2008.

FONSECA, M. S.; ANDRADE, M. H. P.; MORAIS, M. B. Ciências para você - $5^{\circ}$ ano. 3. ed. Curitiba: Positivo, 2007.

GIBIN, G. B.; KIILL, K. B.; FERREIRA, L. H. Categorização das imagens referentes ao tema equilíbrio químico nos livros aprovados pelo PNLEM. Revista Electrónica de Enseñanza de las Ciencias, Vigo, v. 8, n. 2, p. 711-721, 2009.

GUSMÃO, G. A. S.; CAPILÉ, B.; GOLDBACH, T. Reflexões sobre materiais de apoio para atividades práticas para o ensino de biologia: percepções de docentes e de licenciandos. Revista Ciência \& Ideias, Nilópolis, v. 3, n. 1, p. 1-13, 2011. Disponível em: < http:// 200.20.215.200/revista/index.php/revistacienciaseideias/article/viewFile/66/reflexoes >. Acesso em: 27 set. 2011.

JOTTA, L. A. C. V.; CARNEIRO, M. H. S. Malária: as imagens utilizadas em livros didáticos de biologia. In: ENCONTRO NACIONAL DE PESQUISA EM EDUCAÇÃO EM CIÊNCIAS, 7., 2009, Florianópolis. Atas... Florianópolis, ABRAPEC, 2009. Disponível em: <http://www.foco.fae.ufmg.br/pdfs/303.pdf >. Acesso em: 20 set. 2011.

. As imagens da embriologia animal: uma análise em livros didáticos de biologia. In: ENCONTRO NACIONAL DE PESQUISA EM EDUCAÇÃO EM CIÊNCIAS, 5., 2005, Bauru. Atas... Bauru: ABRAPEC, 2005. Disponível em: <http://www.nutes.ufrj.br/ abrapec/venpec/conteudo/artigos/3/pdf/p208.pdf>. Acesso em: 2 jan. 2012.

LEMBO, R.; COSTA, I. Ciências $-4^{\text {a }}$ série. São Paulo: Ática, 2004. 
O sistema respiratório nos livros didáticos ...

LIMA, M. E. C. C.; MAUÉS, E. Uma releitura do papel da professora das séries iniciais no desenvolvimento e aprendizagem de ciências das crianças. Ensaio: Pesquisa em Educação em Ciências, Belo Horizonte, v. 8, n. 2, p. 161-175, 2006. Disponível em: <http:// 150.164.116.248/seer/index.php/ensaio/article/view/115/166>. Acesso em: 16 jan. 2012.

LONGHINI, M. D. O conhecimento do conteúdo científico e a formação do professor das séries iniciais do ensino fundamental. Investigações em Ensino de Ciências, Porto Alegre, v. 13, n. 2, p. 241-253, 2008. Disponível em: < http://www.if.ufrgs.br/ienci/artigos/ Artigo_ID184/v13_n2_a2008.pdf >. Acesso em: 16 jan. 2012.

LORENZETTTI, L.; DELIZOICOV, D. Alfabetização científica no contexto das séries iniciais. Ensaio: Pesquisa em Educação em Ciências, Belo Horizonte, v. 3, n. 1, p. 1-17, 2001. Disponível em: <http://150.164.116.248/seer/index.php/ensaio/article/view/35/ 66>. Acesso em: 16 jan. 2012.

MATOS, S. A. et al. Referenciais teórico-metodológicos para a análise da relação textoimagem do livro didático de biologia: um estudo sobre o tema embriologia. Revista Brasileira de Ensino de Ciência e Tecnologia, Ponta Grossa, v. 3, n. 1, p. 92-114, 2010.

MOHR, A. Análise do conteúdo 'saúde' nos livros didáticos. Ciência \& Educação, Bauru, v. 6, n. 2, p. 89-106, 2000. Disponível em: <http://www.casulo.ufsc.br/admin/arquivos/ 140511-mohr $\% 20 \% 20$ ciencia $\% 20 \mathrm{e} \% 20$ educa $\%$ C3\%A7ao\%202000.pdf $>$. Acesso em: 15 jan. 2012.

MEGID NETO, J.; FRACALANZA, H. O livro didático de ciências: problemas e soluções. Ciência \& Educação, Bauru, v. 9, n. 2, p. 147-157, 2003. Disponível em: <http:// www.scielo.br/pdf/ciedu/v9n2/01.pdf>. Acesso em: 24 jan. 2012.

NASCIMENTO, T. G.; MARTINS, I. O texto de genética no livro didático de ciências: uma análise retórico-crítica. Investigações em Ensino de Ciências, Porto Alegre, v. 10, n. 2, p. 255-278, 2005.

NIGRO, R. G.; AZEVEDO, M. N. Ensino de ciências no fundamental 1: perfil de um grupo de professores em formação continuada num contexto de alfabetização científica. Ciência \& Educação, Bauru, v. 17, n. 3, p. 705-720, 2011. Disponível em: <http:// www.scielo.br/pdf/ciedu/v17n3/a12v17n3.pdf >. Acesso em: 18 jan. 2012.

NIGRO, R. G.; CAMPOS, M. C. C. Ciências - 4ª série. São Paulo: Ática, 2004.

PERALES PALACIOS, F. J. Uso (y abuso) de la imagen en la enseñanza de las ciencias. Enseñanza de las Ciencias, Barcelona, v. 24, n. 1, p. 13-30, 2006.

PERALES PALACIOS, F. J.; JIMÉNEZ VALLADARES, J. D. Las ilustraciones en la enseñanza-aprendizaje de las ciencias: análisis de libros de texto. Enseñanza de las Ciencias, Barcelona, v. 20, n. 3, p. 369-386, 2002.

PORTO, A.; RAMOS, L.; GOULART, S. Asas para voar: ciências - $5^{\circ}$ ano. São Paulo: Ática, 2008. 
Ruppenthal, R.; Schetinger, M. R. C.

SFORNI, M. S. F.; GALUCH, M. T. B. Aprendizagem conceitual nas séries iniciais do ensino fundamental. Educar, Curitiba, n. 28, p. 217-229, 2006. Disponível em: < http:// www.scielo.br/pdf/er/n28/a14n28.pdf>. Acesso em: 17 jan. 2012.

SOUZA, L. H. P.; GOUVEA, G. Imagens da saúde no livro didático de ciências. In: ENCONTRO NACIONAL DE PESQUISA EM EDUCAÇÃO EM CIÊNCIAS, 7., 2009, Florianópolis. Atas... Florianópolis, ABRAPEC, 2009. Disponível em: <http:// www.foco.fae.ufmg.br/pdfs/512.pdf >. Acesso em: 5 jan. 2012.

TERNES, A. P. L.; SCHEID, N. M. J.; GÜLLICH, R. I. C. A história da ciência em livros didáticos de ciências do ensino fundamental. In: ENCONTRO NACIONAL DE PESQUISA EM EDUCAÇÃO EM CIÊNCIAS, 7., 2009, Florianópolis. Atas... Florianópolis, ABRAPEC, 2009. Disponível em: <http://www.foco.fae.ufmg.br/viienpec/ index.php/enpec/viienpec>. Acesso em: 2 jan. 2012.

VASCONCELOS, S. D.; SOUTO, E. O livro didático de ciências no ensino fundamental proposta de critérios para análise do conteúdo zoológico. Ciência \& Educação, Bauru, v. 9, n. 1, p. 93-104, 2003. Disponível em: <http://www.scielo.br/pdf/ciedu/v9n1/ 08.pdf>. Acesso em: 24 jan. 2012.

XAVIER, M. C. F.; FREIRE, A. S.; MORAES, M. O. A nova (moderna) biologia e a genética nos livros didáticos de biologia no ensino médio. Ciência \& Educação, Bauru, v. 12, n. 3, p. 275-289, 2006. Disponível em: <http://www.scielo.br/pdf/ciedu/v12n3/ 03.pdf >. Acesso em: 14 jan. 2012.

Artigo recebido em 12/10/12. Aceito em 18/03/13. 